\title{
ESTRATEGIAS DISCURSIVAS EN LA NARRATIVA BREVE DE CARMEN DE BURGOS
}

(Discursive Strategies in Carmen de Burgos's Brief Narrative)

\author{
Manuel Martínez Arnaldos* \\ Universidad de Murcia
}

\begin{abstract}
The purpose of this article is to study some of the discursive strategies, enunciation and communication processes which, from a writing of journalistic affiliation, allow the best interpretation of the socio-cultural and anthropological context in which Carmen de Burgos's short stories are inserted. Special attention is paid to costumbrista texts, in which a descriptive function stands out, both in the rural environment (Rodalquilar cycle) and in the urban one. In the former, a series of popular expressions and recurrent motifs are formed, which are transmitted as an echo from one story to another; whereas in the latter (in Madrid) the presentation of peculiar types, places of the city, and in regard to the social neglect and degradation of women. Other discourse registers are also analyzed, such as references to cosmopolitanism or to the intimate diary.
\end{abstract}

Key Words: Short Story; Tale; Discourse; Costumbrism; Description; Stereotypes.

Resumen: El propósito de este artículo es estudiar alguna de las estrategias discursivas, procesos de enunciación y comunicación que, desde una escritura de filiación periodística, permiten la mejor interpretación del contexto socio-cultural y antropológico en el que se inscribe la narrativa breve de Carmen de Burgos. Se presta especial atención a los textos costumbristas, en los que destaca consecuentemente la función descriptiva, tanto en los de ambiente rural (ciclo de Rodalquilar) como en el del urbano. En los primeros se configura una serie de expresiones populares y motivos recurrentes, estereotipos que como un eco se transmiten de un relato a otro; mientras que en los segundos (de ambiente madrileño) destaca la presentación de tipos peculiares, lugares de la ciudad y temas que atañen al desamparo social y la degradación de la mujer. También se analizan otros registros del discurso, como los referentes, entre otros, al cosmopolitismo o al diario íntimo.

\footnotetext{
Palabras clave: Novela corta; Cuento; Discurso; Costumbrismo; Descripción; Estereotipos.
}

* Dirección para correspondencia: Manuel Martínez Arnaldos. Facultad de Letras. Campus de La Merced. 30001 Murcia. (mmarnald@um.es) 


\section{Introducción}

Conocida y muy divulgada ha sido la preocupación de Carmen de Burgos por la condición social de la mujer española en su época, expuesta en numerosas conferencias, artículos y ensayos. Inquietud que, en gran medida, va a nutrir o ser germen de buena parte de sus artículos literarios, cuentos, novelas cortas y novelas, subgéneros literarios que implican un discurso que podemos considerar como un sistema de evaluación social. Pero, como todo sistema de comunicación, es preciso reconocer la efectividad de la comunicación y no sólo de su significación. Ello nos lleva a distinguir determinados signos producidos intencionalmente y justificables de los índices que proporcionan una simple interpretación. De ahí que en los textos de los subgéneros literarios aludidos, en cuanto a su modo de organización narrativa, se privilegien formas o tipos como la mera narración, la descripción, el diálogo o la argumentación. A eso habría que añadir un conjunto de factores culturales que son imprescindibles para la comunicación y la eficacia de ésta mediante los efectos y resultados perlocutorios en los receptores, para la consecución de la persuasión y convicción en los lectores a partir de su recepción de los discursos retóricos (Albaladejo 2013: 2). De tal modo, en una enunciación concreta se pueden construir diversos sujetos discursivos que muestran modos de relación diferente entre ellos, diversos puntos de vista, diversas estrategias discursivas, según la actitud del emisor o bien del narrador o personaje, para poner en valor el tema tratado, ya sea de extracción y tono melodramático, romántico, costumbrista, psicológico, cosmopolita o de crítica social, según se advierte en buena parte de la producción de novelas, novelas cortas y cuentos de Colombine. Y el contenido temático, el estilo y la estructura textual son reflejo de las características de la situación comunicativa, del contexto socio-cultural y literario de la época. Pues todo lo que exponemos, todo lo que enunciamos, es el resultado de la actualización de las virtualidades contextuales que entraña toda dialéctica intersubjetiva y que envuelve la totalidad del comportamiento verbal dentro de los sociolectos que articulan el sistema (Ramón Trives 1991: 47-48), como podemos apreciar en algunos de los relatos de Colombine, en especial los de raigambre costumbrista.

Pero más allá del contexto del sistema lingüístico, también es preciso atender al contexto situacional. Un contexto, un medio, ampliamente dominado por el peculiar sistema de producción editorial característico de la época, es decir, por la aparición de muy numerosas colecciones de revistas dedicadas a la publicación de novelas cortas y en las que participan múltiples autores, de los que deriva una ingente producción novelística que habrá de influir en una contaminación formal y temática no ajenas a las expectativas de recepción por parte del lector. Así, los asiduos lectores de la revista $L a$ Novela Corta, tras la lectura de la novela corta de Colombine Un hombre negro $\left(\mathrm{n}^{\circ} 27\right.$, Madrid, 8-VII-1916), en cierto modo habrán de quedar mediatizados por la novela corta que le precede de A. de Hoyos y Vinent, titulada El crimen del fauno $\left(\mathrm{n}^{\circ} 26\right.$, Madrid, 1-VII-1916), y por la que le sigue, Nada menos que todo un hombre (n ${ }^{\circ} 28$, Madrid, 15VII-1916), de Miguel de Unamuno. Ello conlleva que el dispositivo y las condiciones de enunciación del género novela corta están ligadas al marco, el cual les confiere un estatuto comunicativo particular y una finalidad estética y literaria precisa a través de 
su conexión con el contexto social, es decir, el marco aglutina y filtra las condiciones del contexto social en el que se desarrolla. Ello nos permite valorar la situación pragmática del género, asociado, por una parte, a la posición del escritor y, por otra, a la del público-lector (Martínez Arnaldos 1996: 60).

El marco, pues, que suponen las revistas, determina un conjunto solidario en torno al género novela corta, un principio de unión o correlación que puede afectar tanto a la individualidad del autor como a la determinación creadora y a su "voluntad de género" (Albaladejo 1984: 170), no sólo en lo que se refiere a la elección temática de éste sino al funcionamiento de dispositivos y operaciones textuales. Pues la novela corta que aparece bajo el patrocinio o encuadre de la colecciones de revistas literarias se distancia del autor singular y se transforma en colectiva. Se trata de un estatus ya advertido por la propia Colombine, cuando en unas declaraciones a Gil Benumeya le manifiesta que la novela corta se adapta inmediatamente a los nuevos ideales y perdura cuando se hace colectiva; y es, sobre todo, un éxito indiscutible de los novelistas que son periodistas a la vez, como es su caso. La pasión se ha trasladado de lo individual a lo colectivo (Gil Benumeya, "A manera de prólogo", en Carmen de Burgos, Vida y milagros del pícaro Andresillo Pérez, en La Novela de Hoy, no 450, Madrid, 26-XII-1930, pp. 134-136). La novela corta, por tanto, en una buena parte de sus parcelas, es un reflejo del periodismo de la época. Es una novela corta, pues, que en muchas ocasiones transciende hacia una escritura periodística en la que se da la convergencia de una lectura placentera y de una información exacta (Mouriquand 1999: 3). Por ello, la crónica y el reportaje periodísticos, en sus diversas variantes sobre temas de actualidad, van a ser constantemente novelados. Baste un par de ejemplos. Carmen de Burgos, en su novela Los anticuarios (Madrid, Biblioteca Nueva, 1919), luego adaptada a novela corta con el mismo título (Los Contemporáneos, $\mathrm{n}^{\circ}$ 671, Madrid, 1-XII-1921), por medio de sus protagonistas, Adelina y Fabián, se nos muestran las múltiples vicisitudes que acontecen en el mundo de los anticuarios: falsificaciones, expolio de obras de arte en iglesias y conventos, subastas de arte amañadas, etc. Y de manera similar actúa Colombine, ahora en referencia al contrabando en su novela El último contrabandista (Barcelona, Sopena, s.a., c. 1918), también adaptada a los límites de novela corta (Los Contemporáneos, $\mathrm{n}^{\circ} 689$, Madrid, 6-IV-1922), donde se nos exponen las distintas estratagemas de los lugareños, capitaneados por Don Antonio, para eludir la vigilancia de los carabineros y conseguir los fardos con contrabando que los barcos depositan junto a la costa. Desde una perspectiva actual me atrevería a afirmar que los citados relatos representan la base de unos perfectos guiones televisivos para su desarrollo en programas como "Comando Actualidad", de la cadena 1 de TVE, o "En el punto de mira" de la Cuatro TV.

Un perfil periodístico que, en cierto modo, explica que los temas van a ser reincidentes, como clichés literarios, formas estereotipadas (Amossy y Herschberg Pierrot 1997) con una estructura muy limitada en cuanto a sus tipos y tendencias temáticas. Pues el lector, así como el editor, son los que imponen sus gustos y el escritor se somete a ellos, lo que explica una clara tendencia a la literatura de consumo, de mercado. Y lo que los lectores demandan es amenidad, sensacionalismo e intriga, y en especial de tema amoroso y erótico, aunque sin llegar, salvo excepciones, a lo pornográfico. Un ámbito, 
el del erotismo, en el que aparecieron en el mercado diversas colecciones específicas, en algunas de las cuales probó fortuna Colombine, como con sus novelas cortas La confidente y La que quiso ser maja (Pujante Segura 2017: 175-192).

Una novelística corta que, a la vez, es mezcla de costumbrismo, exotismo y cosmopolitismo, de lo vulgar cotidiano y de una acusada inclinación por lo actual y moderno, y por un nuevo despertar de la conciencia social. Así, podemos encontrar múltiples relatos referentes a la imagología y al multiculturalismo. Sirvan unos pocos ejemplos: de Carmen de Burgos, La misionera de Teotihuacán (La Novela Mundial, $\mathrm{n}^{\circ}$ 21, Madrid, 3-VIII1926), ambientada en Méjico, y El dorado trópico (La Novela de Hoy, ${ }^{\circ}$ 404, Madrid, 2-II-1930), enmarcada en La Habana; también Cuba sirve de motivo para la novela corta de A. Hernández Catá, La piel ( El Libro Popular, II, n 18, Madrid, 6-V-1913), donde se nos exponen las diferencias culturales y sentimentales entre un sueco, una criolla y un negro cubano; de manera similar, las insalvables diferencias culturales entre Occidente y Oriente, representadas por una catalana que se casa con un rico filipino, son expuestas por Hernández Catá en El drama de la señorita de Occidente (La Novela Semanal, n ${ }^{\circ}$ 12. Madrid, 10-IX-1921); en otras ocasiones, es el hombre occidental quien engaña y coacciona a una bailarina cubana que obtiene un gran éxito en París, como es el caso del relato de Juan Pujol, La Venus de Ébano (La Novela de Hoy, $\mathrm{n}^{\circ}$ 505, Madrid, 22-I-1932).

También, en lo que atañe a los estudios de género, encontramos un buen ejemplo en la novela corta de Álvaro Retana, Los ambiguos (La Novela de Hoy, $\mathrm{n}^{\circ}$ 9, Madrid, 14- VII-1922), donde se entremezclan el lesbianismo y el mundo gay. Pero a la par de los ejemplos que acabamos de reseñar, apropiados para un estudio en los dominios de la literatura comparada, donde resultan imprescindibles los libros de viajes de Colombine, son otros muchos los ejemplos de variantes temáticas que conforman un amplio panorama del acontecer socio-literario de la época. Ejemplo serían las novelas cortas circunscritas a temas y motivos referidos al costumbrismo, al mundo taurino (entonces en boga), a lo histórico y legendario, a lo amoroso y erótico, a la intriga y lo policiaco, a lo psicológico, a lo humorístico, y un largo etcétera. Una panoplia temática que, como hemos advertido, deriva en una reiteración o similitud en los temas, lo que obliga a los escritores a adoptar diferentes estrategias discursivas en el tratamiento de los temas. Se llegaría, en casos extremos, ante la presión de los editores para disponer en fechas concretas del original demandado, al autoplagio. Y es en referencia a las estrategias discursivas de los autores ante la similitud, en bastantes ocasiones, de los temas, donde queremos proponer algunos casos concernientes a la narrativa breve de Carmen de Burgos.

\section{Costumbrismo}

\subsection{Costumbrismo rural}

Entre ellos queremos destacar, en primer lugar, su novelística de carácter costumbrista, dada su facilidad narrativa y gusto por lo descriptivo, como nos pone de manifiesto en su literatura de viajes. Se trata de novelas cortas costumbristas que podríamos dividir en dos grandes grupos: las de base rural o regionalista y las de la gran urbe o ciudad. 
Entre las primeras destacan las novelas cortas del ciclo de Rodalquilar, acogiéndonos a la propuesta y denominación de Concepción Núñez Rey (Núñez Rey 2005; Núñez Rey 2017). De ellas, me atrevería a afirmar que Églogas (Los Cuentistas, $\mathrm{n}^{\circ}$ 4, Barcelona, 20VIII-1910) constituye como el germen argumental de todas las restantes del ciclo por su esquematismo narrativo. Se trata, permítaseme la catalogación, de un cuento largo más que de una novela corta. Es un cuento preciso y perfectamente estructurado en su trama y acontecer antropológico, que va a tener un eco previo en la novela corta El tesoro del castillo, publicada tres años antes en El Cuento Semanal (n ${ }^{\circ}$ 25, Madrid, 21-VI-1907), y un año posterior, en 1908, en el autoplagio con el título reducido de El tesoro (Cuentos de Colombine, Valencia, Sempere, 1908, pp. 203-260), un texto, este último, en el que la autora o el editor suprimen el diálogo final entre los protagonistas que aparece en la edición de El Cuento Semanal. También encontramos fuertes resonancias sobre la vida rural, cortijos y parajes del valle de Rodalquilar en Frasca, la tonta (El Libro Popular, III, $\mathrm{n}^{\circ}$ 26, Madrid, 30-VI-1914) y en el autoplagio de la misma publicado con el título de Venganza (La Novela Corta, $\mathrm{n}^{\circ}$ 137, Madrid, 17-VIII-1918); así como en Puñal de claveles (La Novela de Hoy, ${ }^{\circ}$ 495, Madrid, 12-XI-1931). De modo similar se inscriben en el mismo espacio las novelas adaptadas a los límites de la novela corta, Los inadaptados (Los Contemporáneos, $\mathrm{n}^{\circ}$ 518, Madrid, 5-XII-1918) y la antes citada El último contrabandista.

Se observa que Carmen de Burgos, como otros autores de su época, por ejemplo, V. Blasco Ibáñez, E. Zamacois, E. Carrère, A. González Blanco o R. León, entre otros, se avienen a los dictados de los editores y no tienen inconveniente en autoplagiarse mediante un cambio en la titulación, en adaptar una novela ya publicada a los límites que imponen las colecciones dedicadas a la publicación de novelas cortas, e incluso a determinadas transformaciones textuales respecto al texto primario u original (Martínez Arnaldos 1982: 71-110).

En su conjunto, las novelas cortas ambientadas en Rodalquilar, al margen del contenido romántico y melodramático y final trágico, excepto El tesoro del castillo, son textos realistas en los que se nos comunican unas sensaciones, unas experiencias ya percibidas o vividas. Nos situamos ante un discurso costumbrista, con un lenguaje descriptivo que bien como signo totalizador textual o como signo independiente en cualquiera de sus niveles, enunciado, frase o palabra, nos atrapa en la realidad de las cosas y nos comunica un sentimiento por el pasado, a la vez que nos libera del mundo actual (Martínez Arnaldos 1979: 65). Por ello, más que atender a rasgos estilísticos, es preferible reparar en el "taxema de experiencia" (Pottier 1977: 107), para mejor valorar la reincidencia de expresiones y de motivos siempre presentes en los textos de los autores costumbristas de una determinada zona geográfica o región. Expresiones populares, temas y motivos (De Gréve 1995: 19-23), sobre todo estos últimos, a los que se acoge Colombine, que como un eco retransmite de un relato a otro. Es decir, son motivos que por su reiteración en diferentes textos de un mismo autor se adhieren a la noción de estereotipos o clichés literarios. Ello implica que deben su fundamento a motivaciones individuales de tipo psicológico, así como a factores sociales (Amossy y Herschberg Pierrot 1997: 38-40), llegando, en ocasiones, el abundante uso de los estereotipos a constituir una especie de circulo vicioso del que es difícil salir, dado su carácter psicodinámico siempre 
presente en el imaginario socio-cultural latente, preformado en etapas anteriores de la vida, tal y como estimamos debe acaecer en el caso de Colombine.

Y entre los motivos destaca el de "la cruz del camino", en referencia a esas cruces de madera que se colocan junto a los caminos para indicar el lugar donde ha muerto alguien. Y los lugareños que pasan junto a ellas, en el caso de los hombres, se quitan el sombrero, mientras que las mujeres se santiguan en señal de respeto a la vez que depositan una piedra junto a la cruz. Y tal motivo lo encontramos en Églogas, en El perseguidor (La Novela Corta, $\mathrm{n}^{\circ}$ 59, Madrid, 17-II-1917), en El puñal de claveles y en el cuento precisamente titulado La cruz del camino (La Esfera, n ${ }^{\circ} 345$, Madrid, 14-VIII1920); aunque en este último relato, la cruz no está en el lindero del camino sino en el centro de un bancal, lo que disgusta al propietario del terreno, José Freniche, por las piedras que en el bancal se acumulan. Freniche, pero con el nombre de Juan, también lo encontramos en Églogas; al igual que los apodos de dos bandidos, "El Pavo" y "El Gallina", muertos por la guardia civil, ya habían sido citados en El perseguidor. Una novela corta esta, por cierto, un tanto desequilibrada en su estructura narrativa y desarrollo argumental, pues tras un inicio en el que la protagonista nos describe las costumbres en los cortijos andaluces, con una amplia descripción de la caza de la perdiz en la serranía de Córdoba, luego marcha a Madrid y posteriormente se dedica a viajar por diversos países y ciudades europeas. Y se sirve del elemental motivo de la soledad de la mujer viajera que, en su imaginación, se siente perseguida por un hombre. Tan débil trama le sirve a Colombine para presentarnos una serie de "postales turísticas" en las que nos describe las ciudades y países que visita: Venecia, Nápoles, Pompeya, Copenhague, Londres, Suiza y Noruega. Y en referencia a la anterior alusión a la caza de la perdiz, podemos constatar la reiteración de tal motivo en la novela Los inadaptados (Valencia, Sempere, 1909), luego adaptada a novela corta (Los Contemporáneos, ${ }^{\circ}$ 518, Madrid, 5-XII-1918), en el cuento Amor de esposa (incluido en la edición de Los inadaptados, pp. 257-262) y en El último contrabandista. Se da la curiosa circunstancia de que el nombre de la perdiz de reclamo en los dos anteriores relatos es el mismo: "Tamberlick".

Otro de los motivos recurrentes es el del desperfollo, cuya descripción aparece en $E l$ tesoro del castillo, y de manera más amplia en Frasca la tonta (Venganza). El uso del cantar imitando o simulando dos voces, cuando un mozo, durante la noche, iba por caminos solitarios, para dar a entender que va acompañado, está presente en Églogas, Frasca la tonta y Puñal de claveles. También son motivos reiterados, el de la trilla, y la costumbre de que los hombres duerman en la era provistos de manta (Églogas y El tesoro del castillo), al igual que la figura de buhonero, quien con su burra cargada de capazos ("capachos") llenos de telas, mantones y baratijas, se dedicaba a visitar los diferentes cortijos para vender su mercancía a las mujeres (Los inadaptados y Puñal de claveles). En cuanto a expresiones o fórmulas populares que se decían para dar por concluida una reunión o velada, cual era la de "¡Roque!, ¡Roque!, ¡Roque!, ¿ha venido Roque?", la encontramos en El tesoro del castillo y en El último contrabandista. Otros ejemplos de motivos que se reiteran podríamos añadir, como los referentes al baile de ánimas, habitáculos de las casas de campo y cortijos, con especial atención al espacio del salón-comedor con su cocina baja de leña como lugar de reunión. 


\subsection{Costumbrismo urbano}

Y si del ambiente rural de los campos de Níjar y de los cortijos de Rodalquilar nos trasladamos a la gran urbe, en concreto a Madrid, a través de novelas cortas como Los negociantes de la Puerta del Sol (La Novela Corta, n. ${ }^{\circ}$ 195, Madrid, 27-IX-1919) y La rampa (Los Contemporáneos, $\mathrm{n}^{\circ} 655,11-\mathrm{VIII}-1921$ ), resumen de la novela del mismo título, publicada en Madrid, en la editorial Renacimiento, en 1917. Se puede comprobar que ambos relatos, en cierto modo, suponen una homogeneidad o complementación del uno respecto al otro en cuanto a la ambientación madrileña y la presencia de tipos representativos, aunque alejadas, en su proceso discursivo, de las típicas novelas cortas de ambiente castizo madrileño de Antonio Casero, Fernando Mora o Pedro de Répide. Pues, en su conjunto, las dos novelas cortas de Colombine constituyen la pintura de un gran fresco, o mejor aún, un cuadro naíf del ambiente madrileño de la época, dotados de una inigualable destreza descriptiva a la hora de matizar trazos y dibujar o caricaturizar a los más diversos tipos. En Los negociantes de la Puerta del Sol se nos permite contemplar la atracción que el lugar ejerce en el protagonista, D. Justo, quien tras vender sus tierras en el pueblo, marcha a Madrid con su familia. D. Justo acude todos los días a la Puerta del Sol, donde contempla el desfile de pícaros y vendedores que por ella deambulan: limpiabotas, vendedoras de periódicos atrasados como si fueran del día, el tipo que ofrece una máquina que transforma un papel blanco en dinero, y timadores de toda índole, como el personaje de Francisco Galán, que engaña en más de una ocasión, con raros negocios, al incauto de D. Justo. Y junto a tal desfile de tipos también encontramos breves descripciones del reloj de la Puerta del Sol y quien lo hizo, de sus campanadas anunciando el año nuevo, la venta de lotería de Navidad, la noche de Reyes, las procesiones que por la plaza desfilan, así como una enumeración de los cafés que existen en la Puerta del Sol y en calles aledañas: Café de Correos, El Nuevo Levante, El Colonial, El Pombo, etc.

En cambio, en La rampa, por medio de sus protagonistas, Isabel y Águeda, en especial la segunda, nos adentramos en lugares y personajes más sórdidos. Por ejemplo, la existencia de un incómodo restaurante de la Puerta del Sol en el que se come un menú por el precio de una peseta, y al que suele acudir Isabel y Águeda, empleadas en un Bazar cercano, al igual que oficinistas y empleados de comercios. También se hace referencia a los cinematógrafos, a cocheros desaprensivos, al consultorio médico denominado "La gota de leche", etc. Y ya situados en las afueras de Madrid, en el barrio de Embajadores, se alude a la ubicación de instituciones allí existentes: Asilos, Casa de Beneficencia, Casa de Maternidad y La Inclusa, centros, alguno de ellos, por los que se ve obligada a pasar Águeda tras quedar embarazada y en la más absoluta pobreza. Es de destacar la fuerza y el realismo expresivo, con un alto sentido crítico, de Colombine, en la descripción de tales instituciones por el trato que en ellas reciben las mujeres pobres y desamparadas por parte de sus administradores: monjas y médicos. Es un oscuro panorama sobre las desdichas de la mujer y la falta de amparo social.

También inciden en el costumbrismo madrileño sus cuentos: La muerte del recuerdo, Por las ánimas, y iAy del solo! (Cuentos de Colombine, Valencia, Sempere c. 1908, pp. 11-21, 23-37 y 75-82, respectivamente). En el primero, Madrid apenas es un telón de fondo para representar los recuerdos amorosos de juventud de un viejo y viudo senador que de manera 
inesperada se vuelve a encontrar con la joven que amó y luego abandonó, pero ella no lo reconoce después de tantos años. En el segundo, Por las ánimas, narración plena de ironía, sí encontramos una interesante descripción sobre las gentes y puestos ambulantes, que en las primeras horas de la mañana se instalan a las puertas del jardín Botánico, y a la vez, en el desarrollo argumental, una fuerte crítica contra los jesuitas y su ejercicio como confesores de las mujeres casadas. El tercero, ; Ay del solo!, se inicia con una bella y amplia descripción del otoño madrileño desde la que se nos muestran a vendedores de libros viejos, quioscos de periódicos, una vendedora de bellotas y un jovenzuelo que vende jilgueros. Un cuento este, de fino lirismo, sobre las consecuencias que acarrea la soledad. Próxima al costumbrismo madrileño podríamos mencionar la novela corta La pensión Ideal (La Novela Corta, n..$^{\circ} 371$, Madrid, 13-I-1923), en la que se nos expone cómo una viuda con cuatro hijas, al quedar sin recursos económicos, se ve obligada a transformar el gran chalet que habitan en una pensión. Se trata de una situación a la que tuvieron que recurrir algunas viudas madrileñas, poseedoras de grandes casonas o mansiones, que ante la falta de medios se dedicaron si no a establecer pensiones, sí a alquilar habitaciones.

En referencia a otras ciudades o capitales españolas y la descripción de sus respectivos ambientes y singulares tipos o personajes que en ellas encontramos, podríamos aludir a La malcasada (Valencia, Sempere, 1923) y al cuento ;Triunfante! (Cuentos de Colombine, cit., pp. 99-109). La malcasada es una novela que, a diferencia de otras de la autora, no fue adaptada a novela corta para su posterior publicación en alguna de las muy numerosas colecciones existentes. Está ambientada en Almería y en ella encontramos múltiples descripciones concernientes al vuelo de las cometas desde los terrados, a las peleas de gallos, a las barcas que llegan a la playa con la pesca del día, a una minuciosa e interesante descripción de una juerga flamenca en la venta "La garrofa", etc. Dada su aludida condición de novela, no nos detenemos en valorar sus aspectos descriptivos. ;Triunfante! se inicia con una amplia descripción de Toledo al atardecer y posteriormente presentarnos sus rincones típicos (el Miradero, Zocodover, viejos palacios, iglesias, conventos y callejuelas), incidiendo Colombine con especial énfasis en destacar la religiosidad que envuelve a Toledo, donde "[...] multitud de curas y canónigos grasientos con sus faldas negras y sus sombreros de teja, parecidos a murciélagos escapados también de los agujeros de viejas iglesias, que iban a extender sus alas como siniestras aves de rapiña [...]" (Cuentos de Colombine, cit., p. 101). Y la llega a calificar como una ciudad incómoda, pues en ella "[...] el pueblo es tan católico, que no existe ninguna casa de baños" (Cuentos de Colombine, cit., p. 101). Conviene advertir al respecto que Carmen de Burgos fue "desterrada" a Toledo para ejercer su profesión de maestra de Enseñanza, lo que tal vez justifique su diatriba contra la ciudad; de ahí que su visión descriptiva de la ciudad y sus gentes sea como un reflejo que proyecta un sentimiento psicológico que llega a desdoblar y hacer compleja la visión del narrador en el texto narrativo (Hamon 1981: 189).

\section{Cambio en la estrategia discursiva}

Un cambio de estrategia discursiva y de registro temático respecto a lo hasta ahora expuesto lo encontramos, en primer lugar, en sus novelas cortas Confidencias (Los 
Contemporáneos, ${ }^{\circ}$ 623, Madrid, 30-XII-1920) y El novenario (Colombine, Mis mejores cuentos, Madrid, Prensa Popular, 1923, pp. 87-133) narradas en forma de diario. Textos, en consecuencia, que se nos presentan bajo la forma de un enunciado fragmentado constituido por una serie de "entradas" en las que el yo refleja una serie de acciones, observaciones, pensamientos y sentimientos, cuyos datos crean una especie de cadena temporal. Una escritura inmediata de la que se excluye toda elaboración previa y con una aparente improvisación. En ocasiones se incluyen momentos en los que prevalece la acción, según podemos comprobar en las dos novelas cortas citadas. Otra de las características que se ha de tener en cuenta es la enunciación subjetiva (predominio de la primera persona y uso de los tiempos del discurso) que coopera, dentro de la ficción, a una mayor veracidad de la forma del diario y a conjugar una ilusión realista más eficaz (Simonet-Tenant 2001: 11-22; Lejeune 1990). La publicación de novelas cortas bajo la forma de diario y, por lo general, de ascendencia de temática psicológica, fue recurrente entre algunos escritores de la época.

En Confidencias, la protagonista, en días diferentes durante un año, nos expone su situación y estado anímico ante las constantes ausencias del marido por negocios. Nunca olvida al marido, pero la soledad y el aburrimiento son determinantes para emprender una relación amorosa con un joven, al que finalmente renuncia, porque según escribe, al final de su diario, "no hay amor como el del marido"; su relación con Manuel, el amante, ha sido una experiencia, pero no quiere un segundo marido. Una interesante visión la que nos facilita Colombine por medio de este relato, en el que la soledad de la mujer le impulsa a buscar amante. En tanto que, en El novenario, ambientada en un balneario de Asturias, donde la protagonista se somete a nueve días de baños en aguas medicinales, por entonces tan boga, ésta nos va narrando su estancia de cada día. Respecto a la anterior novela corta, destaca por una mayor tendencia hacia lo descriptivo: ambiente del balneario, baile de danzantes con motivo de la festividad de San Tiburcio, patrón del lugar, excursión al Santuario del Cristo de Limpias, paseos junto al río, etc. Una cierta relación respecto a la soledad de la mujer, perceptible en los dos anteriores relatos como en otros de Colombine, adquiere especial significación, desde una perspectiva irónica y satírica, en El brote (La Novela Corta, n ${ }^{\circ} 491$, Madrid, 18-IV-1925); aunque, en este caso, la soledad viene impuesta por la cláusula de una herencia que recibe la protagonista, según la cual perdería la fortuna en el momento de casarse, por lo que renuncia a varios pretendientes, hasta que al final decide unirse a un joven inglés que comparte con ella la afición por las flores. Es un hobby de los amantes que aprovecha Colombine para ofrecernos todo un tratado de Botánica: diferentes tipos de flores, sobre todo de rosas, y técnicas para podar e injertar.

Sorprende la capacidad y el rigor de Carmen de Burgos a la hora de documentarse, incluso de manera exhaustiva, para tratar un determinado aspecto más o menos circunstancial al núcleo argumental, como acabamos de ver en El Brote o anteriormente en Los anticuarios. Aunque, por lo general, como decíamos al inicio de nuestra exposición, en su novelística predomina el desamparo de la mujer y su condición social, también hay otras novelas cortas en las que Colombine critica el carácter voluble y frívolo de la mujer, como por ejemplo en La tornadiza (Los Contemporáneos, $\mathrm{n}^{\circ}$ 772, Madrid, 
8-XI-1923). En ella la protagonista, una mujer con fortuna, primero es amante de un joven violinista al que abandona, para después casarse un artista de circo. No obstante, en ocasiones, la ligereza y frivolidad viene determinada por el medio mundano al que accede, como le sucede a la chilena Marta, tras su llegada a Hollywood e integrarse en el mundo de Cinelandia (donde hace referencia a famosas actrices y actores del momento: Pola Negri, R. Valentino, Mary Piford, Dolores del Río, etc.), según el relato Se quedó sin ella (La Novela de Hoy, nº 352, 6-II-1929) .

\section{A modo de conclusión}

Sirvan las diferentes estrategias discursivas y registros de temas y motivos, en especial los de carácter costumbrista, que acabamos de exponer, como ejemplo representativo de la ingente producción de novelas cortas y cuentos llevada a cabo por Carmen de Burgos. Tal vez destaque como uno de los autores más prolíficos durante las primeras décadas del siglo XX, pues tan sólo en los dos géneros aludidos se pueden llegar a contabilizar más de noventa novelas cortas, así como más de cuarenta cuentos.

\section{BIBLIOGRAFÍA}

ALBALADEJO MAYORDOMO, Tomás (1984): “Espresione dell'autore e unitá comunicative nella structura sintattica pragmatica dei testi letterari", Lingua e Stile. N. ${ }^{\circ} 18,1: 167-174$.

(2013): "Retórica cultural, lenguaje retórico y lenguaje literario", Tonos Digital. $\mathrm{N}^{\circ} 25: 1-12$.

AMOSSY, Ruth y HERSCHBERG PIERROT, Anne (1997): Stéréotypes et clichés. Paris: Nathan.

DE GRÉVE, Claude (1995): Éléments de littérature comparée II. Thémes et mythes. Paris: Hachette.

HAMON, Philippe (1981): Introduction à l'analyse du descriptif. Paris: Hachette.

LEJEUNE, Philippe (1990): «Cher cahier...». Paris: Gallimard.

MARTÍNEZ ARNALDOS, Manuel (1979): "Consideraciones lingüístico-críticas sobre el texto costumbrista", Murgetana. № 55: 53-91.

(1982): La novela corta española en el primer tercio del siglo XX. Teoría y práctica. Murcia: Publicaciones Universidad de Murcia.

(1996): "Deslinde teórico de la novela corta", Monteagudo, 3. época. $\mathrm{N}^{\mathrm{o}} 1$ : 47-65.

MOURIQUAND, Jacques (1997): L'écriture journalistique. Paris: PUF.

NÚÑEZ REY, Concepción (2005): Carmen de Burgos "Colombine” en la Edad de Plata de la literatura española. Sevilla: Fundación José Manuel Lara. (ed.) (2017): Novelas del ciclo de Rodalquilar (I, II, y III) de Carmen de Burgos "Colombine. Almería: Instituto de Estudios Almerienses de la Diputación de Almería. 
POTTIER, Bernard (1977): Lingüistica general (teoría y práctica). Madrid: Gredos. PUJANTE SEGURA, Carmen M. (2017): "Ausencias presentes: nombres femeninos en una colección erótica española de los años 20", en M. Gloria Ríos Guardiola y M. Belén Hernández González (eds.): Mujeres con luz. Murcia: Edit. um: 175-192.

RAMÓN TRIVES, Estanislao (1991): "Datos para una propuesta de tipología integrada de estilos enunciativos", en Lingüistica Española Actual, vol. 13. $\mathrm{N}^{\mathrm{o}} 1$ : 47-59.

SIMONET-TENANT, Françoise (2001): Le Journal intime. Paris: Nathan.

\section{PERFIL ACADÉMICO Y PROFESIONAL}

Catedrático de Teoría de la Literatura y Literatura Comparada en la Universidad de Murcia, ha desempeñado su docencia e investigación en torno a la crítica literaria, los géneros literarios, la retórica o la sociología literaria, entre otros campos. Ha sido también IP de proyectos nacionales y colaborador de internacionales, profesor invitado en diferentes universidades españolas (UAM, Cádiz, Málaga, Oviedo, etc.) y extranjeras (Pau, París IV Sorbona, París X Nanterre, Urbino, Eötvös Lorán, etc.), miembro del comité científico de diferentes revistas nacionales (Monteagudo, Tonos Digital, Tropelías, Castilla, $452^{\circ} \mathrm{F}$, Actio Nova), director de catorce tesis doctorales y tesis de licenciatura, TFM y TFG. Ha publicado numerosos estudios, entre los que pueden destacar los libros La novela corta murciana. Crítica y sociología (1993) o Lenguajes, texto y mass-media (1990). Ha dirigido congresos, también sobre el ámbito murciano, como "La transición socio-literaria de Neoclasicismo al Romanticismo en el diario (18271838) de José Musso Valiente" (2002) o "José María Castillo Navarro: vida y obra. El cuento y la novela de su época (1950-1975)" (2008). Además, ha participado en grupos y proyectos de investigación con carácter internacional, como el de Retórica Cultural y el de Análisis interdiscursivo, dirigidos por T. Albaladejo Mayordomo (Universidad Autónoma de Madrid).

Fecha de recepción del artículo: 06-06-2018

Fecha de aceptación del artículo: 29-06-2018 